\title{
Skeletal and Surgical Evidence for Acute Osteomyelitis in Non-Adult Individuals
}

Ana Luisa Santos ${ }^{1}$, Jorge Alejandro Suby ${ }^{2}$

${ }^{1}$ CIAS (Centro de Investigação em Antropologia e Saúde) and Department of Life Sciences, University of Coimbra, Portugal.

${ }^{2}$ CONICET - Laboratorio de Ecología Evolutiva Humana, Departamento de Arqueología, Universidad Nacional del Centro de la Provincia de Buenos Aires, Argentina.

Number of text pages: 19

Number of figures: 4

Number of tables: 3

Abbreviated title: Acute osteomyelitis in non-adults individuals

Key words: acute infection, paleopathology, surgical treatment, pre-antibiotic, Portugal

\section{Address for correspondence:}

Ana Luisa Santos

CIAS and Department of Life Sciences, University of Coimbra, Apartado 3046,

P- 3001401 Coimbra, Portugal

alsantos@antrop.uc.pt

Phone +351239854108

Fax +351239854129

This article has been accepted for publication and undergone full peer review but has not been through the copyediting, typesetting, pagination and proofreading process which may lead to differences between this version and the Version of Record. Please cite this article as, doi: $10.1002 / o a .2276$ 


\section{ABSTRACT}

Osteomyelitis is a non-specific infection of bone and bone marrow. In the past acute osteomyelitis (AO) led to high mortality especially in non-adults. Nevertheless, its diagnosis in archaeological populations is rare. Documented individuals with known cause of death offer a unique opportunity to study this condition. This paper aims to describe the bone lesions in non-adults diagnosed with $\mathrm{AO}$ at the Coimbra University Hospital (CUH) and now belonging to the Coimbra Identified Skeletal Collection (CISC). Moreover, mortality rates and demographic profiles for individuals aged $\leq 18$ years old and diagnosed with $\mathrm{AO}$ in the CUH, between 1923 and 1929, were also determined. The 5 (1\%) non-adults in the CISC with AO listed as cause of death were selected for this study and their bones were analysed macroscopically and radiologically. The skeletal remains of one individual revealed a small area of new bone formation in the shaft of the left femur. Radiography of this bone showed a radio-opaque area in the diaphysis. The other four individuals show evidence of surgical treatment, responsible for many cases of disability in the past. In the 7-year period under analysis, 122 juveniles were diagnosed with osteomyelitis and admitted for surgery at the CUH, 43 (35.2\%) of which were diagnosed with AO. Sixty-five percent of the cases of AO occurred between the ages of 8 and 15 years, with males twice as frequently affected as females, and lower limb bones were involved in $91 \%$ of AO cases. AO was responsible for $76.9 \%$ of the deaths. This study of pre-antibiotic non-adults may help to recognize skeletal signs of $\mathrm{AO}$ and their surgical treatment in unidentified skeletal remains. 


\section{Introduction}

Osteomyelitis is defined as an infection of bone and bone marrow resulting in inflammation, necrosis and new bone formation (Capitanio and Kirkpatrick, 1970; Aufderheide and Rodríguez-Martín, 1998; Ortner, 2003; Lazzarini et al., 2004). Although the causative agent is mainly Staphylococcus aureus, other microorganisms, like fungi, viruses and multicelled parasites can be involved (Trueta, 1959; Mast and Horwitz, 2002; Gutierrez, 2005; Labbé et al., 2010). Consequently, it has been considered a non-specific infection in paleopathology (Ortner, 2003; Lewis, 2006).

The pathogens may infect the skeleton by a traumatic or surgical wound, by adjacent soft tissue infection or via a haematogenous route (Capitanio and Kirkpatrick, 1970; Mast and Horwitz, 2002; Ortner, 2003; Labbé et al., 2010). If non-haematogenous, the infection is commonly limited and localized in the long bone diaphysis, affecting the cortex and periosteum, though not necessarily spreading to the medullary cavity (Ortner, 2003; Labbé et al., 2010). In contrast, in the haematogenous osteomyelitis the medullary cavity is affected and the infection may result in necrosis of the original cortex, known as a sequestrum (Harik and Smeltzer, 2010). This is then expelled through a draining subperiosteal abscess or cloaca, producing a suppurative local inflammation (Capitanio and Kirkpatrick, 1970; Ortner, 2003;

Lewis, 2006; Labbé et al., 2010). Moreover, the periosteum is stimulated to create new bone, or an involucrum, which tends to enclose the infected area and perforated by the abscess (Aufderheide and Rodríguez-Martín, 1998; Mast and Horwitz, 2002; Ikpeme et al., 2010).

Although osteomyelitis could occur at any age, the haematogenous form is more common in children, while skeletal growth is most active (Costa, 1936; Lima, 1937;

Capitanio and Kirkpatrick, 1970; Dahl et al., 1998). In the majority of cases the infection is limited to one bone (Ortner, 2003; Riise et al., 2008), affecting mainly tibia and femur, 
followed by the humerus or radius in that order of frequency (Dahl et al., 1998; Labbé et al., 2010). Moreover, a predominance of males over females is observed (Costa, 1936; Lima, 1937; Capitanio and Kirkpatrick, 1970; Gutierrez 2005). Dependent on the duration of the infection, osteomyelitis can be classified in two different stages: acute and chronic. Acute osteomyelitis (AO) is usually diagnosed within two weeks of the onset of symptoms, which presents suppurative infection, edema and vascular congestion (Lew and Waldvogel, 2004).

Also, sequestra can be formed when the medullary and periosteal blood supplies are compromised (Lew and Waldvogel, 2004; Calhoun and Shirtliff, 2009). This form is particularly relevant in non-adults because haematogenous acute osteomyelitis can cause septicaemia and kill before chronic osteomyelitis can develop, representing a potentially major cause of death in the past (Shandling, 1960; Lewis, 2006). In contrast, chronic cases, which can evolve over months or years, are characterized by the persistence of microorganisms, low-grade inflammation, the presence of sequestra and a fistilous tract (Lew and Walvogel, 2004). However, this form may not produce a sequestrum, but instead spreads extensively through the bone inciting osteoblastic activity, expanding the contours of the bone and reducing the size of the medullary cavity (Steinbach, 1966). In these cases, the bone lesion is referred to as sclerosing osteomyelitis or osteitis (Steinbach, 1966). Moreover, in non-adults osteomyelitis may be present without the formation of an involucrum or a readily identifiable cloaca, as pus is leached through the bone easily without subsequent vascular pressure and bone necrosis (Capitanio and Kirkpatrick, 1970; Lewis, 2006). Consequently, identifying the presence or type of osteomyelitis in palaeopathological cases is challenging (Aufderheide and Rodríguez-Martín, 1998; Ortner, 2003). Indeed, although a high mortality (above 20\%) due to haematogenous $\mathrm{AO}$ is reported in the pre-antibiotic clinical literature (Bancroft, 1921; Amberg and Ghormley, 1934), only a small number of non-adult skeletons 
have been diagnosed with osteomyelitis in the archaeological record (see for example Ortner, 2003; Lewis, 2006).

Acute osteomyelitis was a severe health problem before antibiotics. However, complications continued to be reported after the advent of antibiotics, especially in cases caused by Staphylococcus aureus which did not respond to penicillin (Shandling, 1960). Today, although many of these problems have been resolved, thereby reducing their incidence (Dahl et al., 1998; Riise et al., 2008) but it is still an important medical problem (Riise et al., 2008; Ikpeme et al., 2010; Peltola et al., 2010), primarily due to pathogen evolution (Calhoun and Shirtliff, 2009). An example is the recently detected community of methicilin-resistent $S$. aureus is changing the epidemiology and treatment of AO (Harik and Smeltzer, 2010; Kaplan, 2010).

The study of AO in the pre-antibiotic era is the key to understanding the evolution of this disease. In this context, skeletal and documentary evidence can offer information about the impact and distribution of bone infections in past populations for which no historical records are available. Considering the problems of $\mathrm{AO}$ diagnosis in skeletal remains, identified collections, with known-age and sex individuals with accompanying clinical information, offer a unique opportunity to study pathological lesions known to be associated with the cause of death, as well as being a unique source fot the study of treatment. Therefore, these collections can help us to improve the differential diagnosis and answer questions about the nature of stress and survival in past populations.

This article offers a study of skeletal remains from five documented non-adults with $\mathrm{AO}$ listed as cause of death, with the aim to describe the bone lesions therein produced and to help paleopathologists identify possible surgical treatment for AO in skeletons. Also presented is documentary evidence of mortality rates for non-adults diagnosed with 
osteomyelitis and admitted for surgery at the Coimbra University Hospital (CUH) between 1923 and 1929. The distribution of limb bones affected by AO is also presented.

\section{Materials and Methods}

The Coimbra Identified Skeletal Collection (CISC), curated at the University of Coimbra, is comprised of 505 individuals collected in the first half of the 20th century (Rocha, 1995). All the skeletons, exhumed from the Municipal Cemetery of Conchada (Coimbra, Portugal), belong to individuals who died before the introduction of antibiotic therapy (Santos, 2000). Biographic data, including age, sex and cause of death are available for each individual. For this study all individuals with AO listed as the cause of death were selected. The sample consists of $5(1 \%)$ individuals, aged between 8 and 16 years old. Bone changes produced by $\mathrm{AO}$ and the evidence of surgical treatment performed on these individuals were macroscopically and radiographically analyzed. In addition, patients records compiled during the individuals' hospitalization at the Coimbra University Hospital (CUH), in the 1920's, available at the University Archive, were also included as sources of information.

In order to determine the demographic profile and mortality rate of non-adults diagnosed with osteomyelitis, the surgical statistics of CUH accessible for the period between 1923 and 1929 were consulted. Thus, for all affected patients aged between birth and 18 years of age, sex, bone affected and treatment were also recorded. Moreover, for the cases of AO the surgical procedure performed and respective mortality rates were determined.

\section{Results}

Osteological sample 
Five skeletons from the Coimbra Identified Skeletal Collection (CISC) were patients diagnosed with AO at CUH (Table 1). However, the aetiology of the infection was not reported in the hospital records.

Individual number 278 was a 12 years old female. The only bone lesions observable in this skeleton consist of a focal lesion of woven bone on both the proximal and lateral parts of the left femoral diaphysis (Fig. 1A), ca. $4 \mathrm{~cm}$ in length and $2 \mathrm{~cm}$ in width (Fig. 1B).

Radiography of this bone showed a radio-opaque area in the lower portion of the diaphysis of the left femur (Fig. 1C and D). According to CUH records, she died the day after admittance due to "super-acute septicaemia".

Two individuals were admitted with OA and treated by resections. Skeleton 100A, an 11-year old male, had ca. $15 \mathrm{~cm}$ of the mid-section and part of the proximal diaphysis of the right tibia entirely removed (Fig. 2A). It is presumed that the portion of bone resected was affected by AO. The proximal metaphysis showed an irregular cut mark, deeper laterally, with a posterior irregular cavity of $1.5 \mathrm{~mm}$ in length (Fig. 2B). An incomplete cut mark of $1 \mathrm{~cm}$ in length and $1 \mathrm{~mm}$ depth is observed $5 \mathrm{~mm}$ below the removed bone (Fig. 2C). These marks were a result of the surgical technique performed on the bone. Skeleton 220 belonged to a 16year old male, who was also treated with a resection of $c a .7 \mathrm{~cm}$ of the proximal upper diaphysis of his left humerus. A slight area of woven bone is observed in the lateral portion of the proximal metaphysis. The distal end of the humerus showed a regular cut, with a posterior projection of approximately $1 \mathrm{~cm}$. Like the previous case, there is also an incomplete posterior cut, $1 \mathrm{~cm}$ in length, related to surgical technique. In these two cases there is no evidence of bone remodelling surrounding the borders of the shafts.

Two individuals were treated by a surgical technique described as trepanation in the surgical records from the $\mathrm{CUH}$, that consisted of opening the bone for pus drainage from the subperioteal abscess (Pimenta, 1940). Skeleton 126 was that of an 8-year old male, has a 
surgical drainage hole localised in the anteriormedial portion of the proximal diaphysis of the right tibia which was $6 \mathrm{~cm}$ in length and $2.5 \mathrm{~cm}$ in width. The bone was removed by trepanation, exposing the marrow cavity. The fifth case, skeleton 346, belonged to a female patient who died at the age of 10-years and who was diagnosed with acute osteomyelitis of the right tibia. Bone tissue measuring approximately $6 \mathrm{~cm} \times 2 \mathrm{~cm}$ was removed by trepanation from the anteromedial proximal diaphysis and involving the marrow cavity (Fig. 3). Below the area subjected to surgery is a region with a slight woven periosteal reaction measuring 2 $\mathrm{cm}$ in length and $1 \mathrm{~cm}$ in width. In both cases, there is no evidence of remodelling at the margins of the trepanation.

\section{Documentary evidence}

The available surgical statistics from the CUH for the years 1923-1929 with osteomyelitis as the cause of death were analysed. During this seven year period, 122 non-adults were operated on due to osteomyelitis (Table 2), with a male/female ratio of approximately $2: 1$. AO was diagnosed in 43 (35.2\%) individuals, while 79 (64.8\%) were chronic cases. The mean age at surgery (12.6 years) was identical for individuals with the two types of the disease. As a consequence of the infection, 13 of these individuals (10.7\%) died in the $\mathrm{CUH}, 10$ of them (76.9\%) due to the acute form. Five are held in the CISC and specifically discussed here. Of the individuals diagnosed with AO (Fig. 4), 65.1\% (28/43) of the cases involved non-adults between 8 and 15 years old. The bones of the lower limbs were the most affected (91\% of the cases, 39 out of 43$)$, in particular the tibia $(61.3 \%)$ and the femur $(27.3 \%)$, while bones of the upper limb were involved in four individuals (9.1\%). Only one patient had two bones affected, a radius and a tibia. 
To treat cases of $\mathrm{AO}$, the most common form of surgery at CUH was trepanation $(53.5 \%)$, followed by resection (37.2\%) of part of the infected bone (Table 3$)$. Incision, sequestrectomy or osteoclasia were less frequently (9.3\%) used. Eighty percent of the surgical treatments occurred between 24 and 48 hours after the patient's admittance at CUH. Ten $(23.5 \%)$ of the cases diagnosed with $\mathrm{AO}$ died: five after bone resection and five after trepanation. The four individuals treated using incisions or sequestrectomy all survived. Three patients died within the first 24 hours after resection and the other two died during the next 8 days. Among patients who died after trepanation, tree died after between 48 and 72 hours, two died within the first week and one two months after surgery. The anaesthetic used in $85 \%$ of the AO cases treated at the CUH was ethyl chloride or Kélène. Nine of the 10 deaths occurred when ethyl chloride was used as anaesthetic while chloroform was used in individual number 220. Furthermore, two of five individuals from the CISC died the same day as the surgery.

\section{Discussion}

\section{(1) \\ (1)}

Acute osteomyelitis was a prevalent health problem during the pre-antibiotic era, particularly due to limited treatment options, lack of knowledge about its aetiology and difficulties in its diagnosis, all of which added to a high likelihood of death. Thus, the study of AO cases before effective chemotherapy provides an insight into the epidemiology and the progress of this disease. Unfortunately, this kind of bone infection is scarcely reported in skeletal remains because the non-specificity of its lesions, especially when cloaca are not visible, and because it can cause death before bone reactions occur. The identified skeletal collections offer the chance to learn and to improve the diagnosis of AO in skeletal remains, especially in cases like these, in which the individuals received medical care and cause of death was known. In the current study, it was impossible to find out the diagnostic procedures 
applied to the patients at CUH. Nevertheless, it is known that the teaching of microbiology in University of Coimbra began in 1882-1883, and a few years later a laboratory of microbiology was created (Universidade de Coimbra, 1937). In 1901 the 'Radioscopy and Radiography Office' was developed, as an appendix of the course 'Introduction to Medicine and Surgery' ('Propedêutica Médica e Cirúrgica'), and re-equipped in 1915 (Ramalho, 1946). Consequently, laboratory and radiographic analyses were available in $\mathrm{CUH}$ in the period when the patients included in this study were admitted: both analytical tools may have been used at that time in the diagnosis of AO.

In the only individual (sk. 278) with no bone removed (Fig. 1), because she died prior to surgery, there was a minor periosteal reaction visible macroscopically. The short time between the onset of infection and the death of the individual most likely did not allow for the formation of a sequestrum and abscess; both important tools for paleopathological diagnosis. The radiograph of this individual's left femur (Fig. 1C) shows an area of radiodensity. No radiological signs of bone remodelling are evident. This bone, as the rest of the skeleton, is well preserved so the chance of it being an artefact of the radiograph is unlikely. According to clinical evidence, classic bone destruction and periosteal bone formation are not seen in plain radiographs until 10-12 days after the onset of symptoms (Blickman et al., 2004; Pineda et al., 2009), although early subtle changes may be not obvious within 5 to 7 days in children (Pineda et al., 2009). Moreover, in subacute osteomyelitis, diagnosed two weeks after the onset of symptoms (Harik and Smeltzer, 2010), abscesses typically involve the medullary cavity and lytic areas surrounded by reactive sclerosis are usually present in plain radiographs (Mellado Santos, 2006). No bone remodelling or radiological signs compatible with osteomyelitis were found in Sk. 278. Although traumatic or postmortem damage cannot be completely rejected, the bone is externally well-preserved and there are no visible traumatic 
lesions. Therefore, this area of radiodensity is more likely the image of the femoral nutrient vessel (Smitham et al., 2009).

Before the development of antibiotics, surgery was considered the best therapy for AO by some surgeons in Portugal as elsewhere, whereas others advocated for more conservative management (Holman, 1934; D’Abreu, 1937). Factors such as the severity of the diagnosis and the age of the patient were also considered before surgery was chosen (Amberg and Ghormley, 1934; Pimenta, 1940). According to Pimenta (1940), for many years bone trepanation, for facilitation of pus drainage, was the method of choice to treat AO. However, its use was controversial (Costa, 1936; Lima, 1937; Mendes, 1933) with some physicians advising its use in less severe cases of infection while surgical resection was preferred when necrosis occurred (Mendes, 1933). Others, such as Costa $(1936 ; 1941)$, exclaimed the inefficiency of trepanation and thus recommended surgical resection. Surgery is still used to treat acute osteomyelitis in children today (Labbé et al., 2010).

In the present study, of the five non-adult skeletons studied, two were treated by trepanation, with opening of around $6 \mathrm{~cm}$ in length, while and the other two had portions of long bone diaphyses resected $(15 \mathrm{~cm}$ on the tibia and $7 \mathrm{~cm}$ on the humerus). Small cut marks occur approximately $1 \mathrm{~cm}$ below the borders of the long bones resected and are part of the surgical technique. Thus, their size and location allows them to be distinguished from an autopsy procedure. Due to the nature of the treatment in these four cases, it is impossible to know what the bone surfaces originally looked like because they were removed. The remaining diaphyses do not present signs of bone necrosis. Nonetheless, these cases allow the size of the affected areas to be estimated. According to Costa (1941), the bone resected must be larger than the lesion in order to avoid recidivism. This procedure was practiced for the first time in 1701, by Vigaroux in Montpellier, on a tibia with osteomyelitis (Costa, 1941). As a consequence of the surgical resection individuals may have became severely handicapped. 
In many cases mutilation and the use of a crutch were the cost of survival (Costa, 1936; 1941).

The documentary evidence revealed that the majority of patients at CUH with surgical intervention for $\mathrm{AO}$ were subjected to trepanation $(53.5 \%, \mathrm{n}=23)$, followed by resection $(37.2 \%, \mathrm{n}=16)$. Resection demonstrated a higher mortality $(31.3 \%)$ than trepanation $(21.7 \%)$, although this may be a consequence of the clinical status of the patients and not related to the reatment itself. Two patients treated with resection died on the day of surgery, although it is not clear from hospital documents if they died during or after the surgery. All four patients (Table 3) treated with incisions/ sequestrectomy survived and left the CUH listed as "cured". At present, incision and surgical drainage are performed only when a subperiosteal abscess is present (Darville and Jacobs, 2004; Kaplan, 2010).

For the individuals from the CISC subject to trepanation or resection, there is no visible bone reaction adjacent to the areas of bone removed because they died soon after their surgeries. In post-medieval samples, the absence of bone remodelling in the cases of trepanation can be misinterpreted as post mortem damage and the resection confused with the result of an autopsy.

A focal area of woven bone was visible macroscopically on the femur of skeleton number 278 , the individual who died before surgery. If this bone was found in an archaeological specimen it is highly unlikely that a diagnosis of osteomyelitis would be suggested. Moreover, due to funds and time constraints, radiographic analysis is frequently neglected. Thus, cases like this demonstrate the likelihood that non-adult infection may be under-diagnosed in archaeological contexts. The paleopathological identification of AO in children's remains may benefit if all the bones showing new bone formation are radiographed. The radiograph should reveal, first subperiosteal resorption, 'creating radiolucencies with cortical bone that then may progress to irregular destruction with periosteal new bone 
formation’ (Blickman et al., 2004:L57; also see Capitanio and Kirkpatrick, 1970; Mellado Santos, 2006). However, as Resnick and Kransdorf (2005) pointed out radiological diagnosis of $\mathrm{AO}$ is difficult. The data on $\mathrm{AO}$ cases in children at $\mathrm{CUH}$ are consistent with the reported information offered by physicians at that time. The documentary evidence shows that $65 \%$ of the individuals affected were aged between 8 and 15 years old, which concurs with the ages reported in the pre-antibiotic series studied (Amberg and Ghormley, 1934) and in current epidemiological surveys (Gutierrez, 2005). The proportion of male to female non-adults displaying pathologies could provide information about their susceptibility to disease and cultural views on gender (Lewis, 2006). Between 1923 and 1929 the cases of AO reported in the CUH surgical statistics were more frequent in males than in females (2:1), a proportion similar to that found in other studies (Farr, 1926; Amberg and Ghormley, 1934) while Ortner $(2003: 181)$ referred to a ratio of at least $3: 1$.

In relation to bones affected by $\mathrm{AO}$, the current study (Fig. 4) is in accordance with the literature (e.g. Ortner, 2003; Labbé et al., 2010). In 42 cases (97.7\%) the infection was diagnosed on a single bone and the lower limb was the most frequently affected $(91 \%$ of the cases), with the tibia (61.3\%) followed by the femur (27.3\%). Only four bones from the upper limb were affected.

Concerning the localization of the infection in the skeletal sample, the metaphysis/diaphysis of the lower limb bones were the most commonly affected. Therefore, the locations in femora and tibiae found in this study are consistent with clinical data from both the pre- (Homans, 1912; Farr, 1926; Holman, 1934) and post-antibiotic era (Lew and Waldrogel, 2004; Labbé et al., 2010). When the epiphysis is involved, it is usually the result of a primary focus of infection, whereas secondary infection of the epiphysis due to a spread from the metaphysis is rare after 12-18 months of age (Blickman et al., 2004; Lewis, 2006). Nowadays, although mortality due to AO is close to zero in many countries, different 
frequencies are observed by patient series (Gutierrez, 2005). The mortality at the CUH between 1923 and 1929 was relatively high (23.3\%), when compared to frequencies ranging from 5\% (Amberg and Ghormley, 1934) to 25\% (Shandling, 1960), which indicated that mortality depends on the age of the patient, the stage of infection and the treatment employed (;). Unfortunately, information about the specific cause of death of the patients studied here was not found, consequently it is not known whether they died due to surgery, which was mainly drastic and immediate, or due to the advanced state of infection, or more probably, a combination of both. Nevertheless, the anaesthesia cannot be ruled out as the possible cause of death. Ethyl chloride, or Kélène, represented a risk in itself, as was reported on many occasions (Murray, 1965). Furthermore, the surgeon that practiced 54\% of the operations on the non-adult patients with acute osteomyelitis ( 22 of the 43 patients treated), studied the acidosis of different anaesthetics employed in CUH (Zamith, 1928). He concluded that ethyl chloride was appropriate as a general anaesthetic. Further experimental and clinical studies, demonstrated the negative cardiac effect of this drug leading to its later use purely as a local anaesthetic (Murray, 1965).

\section{Conclusions}

Acute infections are known to be major causes of death in the past, especially in non-adults.

This study performed on five non-adults with documented cause of death confirms the difficulty of diagnosing acute osteomyelitis in skeletal remains. In four of these cases the bone affected was surgically removed, either with trepanation or resection. Although, it is impossible to know the macroscopic appearance of the bone removed, the dimensions and the locations of the lesions were recorded. Moreover, there was no bone formation spreading to the shaft as is commonly shown in paleopathological publications, confirming the difficulty 
of AO diagnosis in archaeological samples. Even though plain radiographs could not be used to reveal classic bone destruction in the first stages of the disease in this study, radiographic examination is important to identify cases with no apparent external signs of infection.

Before antibiotics, treatment of both acute and chronic osteomyelitis included surgical removal of part of the bone affected, which can lead to permanent physical disability of the affected limb. The presence of cut marks near the borders of the shaft removed may allow for the identification of surgical resection in individuals who lived after the $18^{\text {th }}$ century AD.

The survey performed of the CUH records reveals that in individuals 18 years old and younger, the chronic form of osteomyelitis was associated with twice the number of cases admitted for surgery in comparison to acute osteomyelitis. Nevertheless, the mortality rate for AO was 6 times higher than that of the chronic form. Until the early $20^{\text {th }}$ century anaesthesia may have also been responsible for some deaths. Males were more commonly affected than females for both forms of osteomyelitis while the mean age is similar. Acute osteomyelitis affected the lower limb ten times more frequently than the upper limb, with the tibia the bone most commonly affected, followed by the femur and radius. Only one individual was diagnosed with two bones affected.

This work demonstrates that the study of identified skeletons and medical documents from the pre-antibiotic period provides useful data for the paleopathological identification of acute osteomyelitis and their surgical treatment in osteological samples.

\section{Acknowledgements}

We would like to thank the Clínica Universitária de Imagiologia at the Coimbra University Hospital, Teresa Alcobia and the Biblioteca das Ciências da Saúde, and the Department of Life Sciences, University of Coimbra. A National Council of Science of Argentina 
(CONICET) fellowship was awarded to the second author. Thanks are also due to Charlotte Henderson, to João Rosa and to the anonymous reviewers for their important comments and English edits.

\section{References}

Amberg S, Ghormley RK. 1934. Osteomyelitis among children. The Journal of Pediatrics 5: $177-193$

Aufderheide AC, Rodríguez-Martín C. 1998. The Cambridge Encyclopedia of Human Paleopathology. Cambridge University Press: Cambridge.

Bancroft FW. 1921. Acute haematogenous osteomyelitis. Annals of Surgery 73: 681-700.

Blickman JG, van Die CE, de Rooy JWJ. 2004. Current imaging concepts in pediatric osteomyelitis. European Radiology 14: L55-L64.

Calhoun JH, Shirtliff M. 2009. Osteomyelitis of the long bones. Seminars in Plastic Surgery 23: $59-72$.

Capitanio MA, Kirkpatrick JA. 1970. Early roentgen observations in acute osteomyelitis. American Journal of Roentgenology 108: 488-496.

Costa AN 1936. Acêrca do tratamento da osteomielite aguda dos adolescentes. Coimbra Médica 8: 579-586.

Costa AN 1941. Novas directrizes no tratamento da osteomielite. Coimbra Médica 2: 103 128.

D’Abreu AL. 1937. Diaphysectomy in acute osteomyelitis. Lancet 229: 1454-1458.

Dahl L, Høyland AL, Dramsdahl H, Kaaresen PO.1998. Acute osteomyelitis in children: a population-based retrospective study 1965 to 1994. Scandinavian Journal of Infectious Diseases 30:573-577. 
Darville T, Jacobs RF. 2004. Management of acute hematogenous osteomyelitis in children.

The Pediatric Infectious Disease Journal 23: 255-257.

Farr CE. 1926. Acute osteomyelitis in children. Annals of Surgery 83: 686-692.

Gutierrez K. 2005. Bone and joint infections in children. Pediatric Clinics of North America 52: $779-794$.

Harik NS, Smeltzer MS. 2010. Management of acute hematogenous osteomyelitis in children. Expert Review of Anti-Infective Therapy 8: 175-181.

Holman CC. 1934. The nature and treatment of acute osteomyelitis. Lancet 224: 867-869.

Homans J. 1912. Osteomyelitis of the long bones. Annals of Surgery 55: 375-387.

Ikpeme IA, Ngim NE, Ikpeme AA. 2010. Diagnosis and treatment of pyogenic bone infections. African Health Sciences 10: 82-88.

Kaplan S. 2010. Acute hematogenous osteomyelitis in children: differences in clinical manifestations and management. The Pediatric Infectious Disease Journal 29: 1128-1129.

Labbé JL, Peres O, Leclair O, Goulon R, Scemama P, Jourdel F, Menager C, Duparc B, Lacassin F. 2010. Acute osteomyelitis in children: The pathogenesis revisited? Orthopaedics \& Traumatology: Surgery \& Research 96: 268-275.

Lazzarini L, Mader JT, Calhoun JH. 2004. Osteomyelitis in long bones. Journal of Bone and Joint Surgery 86: 2305-2318.

Lew DP, Waldvogel FA. 2004. Osteomyelitis. Lancet 364: 369-379.

Lewis ME. 2006. The bioarchaeology of children: Perspectives from Biological and Forensic Anthropology. Cambridge University Press: Cambridge.

Lima R. 1937. O tratamento da osteomielite aguda dos adolescentes. A Medicina

Contemporânea 12: 160-162.

Mast NH, Horwitz D. 2002. Osteomyelitis: a review of current literature and concepts.

Operative Techniques in Orthopaedics 12: 232-241. 
Mellado Santos JM. 2006. Diagnostic imaging of pediatric hematogenous osteomyelitis:

lessons learned from a multi-modality approach. European Radiology 16: 2109-2119.

Mendes E. 1933. A ressecção sub-perióssea no tratamento das osteomielites. Portugal Médico

25: 309-323.

Murray LJI. 1965. Ethyl chloride. British Journal of Anaesthesia 37: 667-670.

Ortner DJ. 2003. Identification of pathological conditions in human skeletal remains. Elsevier Science/Academic Press: New York.

Peltola H, Pääkkönen M, Kallio P, Kallio MJT. 2010. Short-versus long-term antimicrobial treatment for acute hematogenous osteomyelitis of childhood. The Pediatric Infectious Disease Journal 29: 1123-1128.

Pimenta DB. 1940. Tratamento das osteomielites agudas. Clínica, Higiene e Hidrologia 6: 5358.

Pineda C, Espinosa R, Pena A. 2009. Radiographic imaging in osteomyelitis: the role of plain radiography, computed tomography, ultrasonography, magnetic resonance imaging, and scintigraphy. Seminars in Plastic Surgery 23: 80-89.

Ramalho F. 1946. História do Laboratório de Radiologia da Faculdade de Medicina de Coimbra. Coimbra Médica 13: 29-48.

Resnick D, Kransdorf MJ. 2005. Osteomyelitis, septic arthritis, and soft tissue infection: mechanisms and situations. In Bone and Joint Imaging, D Resnick and Kransdorf MJ (eds.). Elsevier Saunder: Philadelphia; 713-742.

Riise ØR, Kirkhus E, Handeland KS, Flatø B, Reiseter T, Cvancarova M, Nakstad B, Wathne K-O. 2008. Childhood osteomyelitis-incidence and differentiation from other acute onset musculoskeletal features in a population-based study. BMC Pediatrics 8: 45.

Rocha MA. 1995. Les collections ostéologiques humaines identifiées du Musée Anthropologique de l'Université de Coimbra. Antropologia Portuguesa 13: 7-38. 
Santos AL. 2000. A skeletal picture of tuberculosis: macroscopic, radiological, biomolecular, and historical evidence from the Coimbra Identified Skeletal Collection. [Unpublished Ph.D. thesis]. University of Coimbra: Coimbra.

Shandling B. 1960. Acute haematogenous osteomyelitis: a review of 300 cases treated during 1952-1959. South African Medical Journal 34: 520-524.

Smitham PJ, Perkins C, Williams M, Eastaugh-Waring S. 2009. Polymethylmethacrylate extrusion into the femoral nutrient vessel during arthroplasty: a phenomenon to be aware of. Radiology Case 3: 20-22.

Steinbach H. L. 1966. Infections in bones. Seminars in Roentgenology 1: 337-369. Trueta J. 1959. The three types of acute haematogenous osteomyelitis: a clinical and vascular study. Journal of Bone Joint Surgery 41-B: 671-680.

Universidade de Coimbra. 1937. Ligeiro resumo histórico sôbre o Laboratório de Microbiologia e Química Biológica. IV Centenário da Universidade de Coimbra: Coimbra. Zamith L. 1928. Anestesia e acidose post-operatória. Arquivos de Cliníca Cirúrgica 1: 343366. 
Table 1. Documented non-adult individuals diagnosed with acute osteomyelitis.

\begin{tabular}{|c|c|c|c|c|c|}
\hline $\begin{array}{l}\text { Skeleton } \\
\text { number }\end{array}$ & Sex & $\begin{array}{l}\text { Age } \\
\text { (years) }\end{array}$ & Diagnosis & $\begin{array}{l}\text { Surgical } \\
\text { treatment }\end{array}$ & $\begin{array}{c}\text { Year of } \\
\text { death }\end{array}$ \\
\hline 278 & $\mathrm{~F}$ & 12 & $\begin{array}{l}\text { Acute } \\
\text { osteomyelitis } \\
\text { of left femur }\end{array}$ & No & 1928 \\
\hline $100 \mathrm{~A}$ & M & 11 & $\begin{array}{l}\text { Acute } \\
\text { osteomyelitis } \\
\text { of the right } \\
\text { tibia }\end{array}$ & Resection & 1926 \\
\hline 220 & M & 16 & $\begin{array}{l}\text { Acute } \\
\text { osteomyelitis } \\
\text { of the left } \\
\text { humerus }\end{array}$ & Resection & 1926 \\
\hline 126 & M & 8 & $\begin{array}{l}\text { Acute } \\
\text { osteomyelitis } \\
\text { of the right } \\
\text { tibia }\end{array}$ & Trepanation & 1926 \\
\hline 346 & $\mathrm{~F}$ & 10 & $\begin{array}{l}\text { Acute } \\
\text { osteomyelitis } \\
\text { of the right } \\
\text { tibia }\end{array}$ & Trepanation & 1929 \\
\hline
\end{tabular}


Table 2. Distribution by sex, mean age, and mortality rate of the non-adults admitted for surgery at the Coimbra University Hospital, between 1923 and 1929, due to acute or chronic osteomyelitis

\begin{tabular}{|c|c|c|c|c|c|c|c|c|c|c|}
\hline \multirow{3}{*}{ Type } & \multirow{2}{*}{\multicolumn{2}{|c|}{ Cases }} & \multicolumn{4}{|c|}{ Sex } & \multicolumn{2}{|c|}{ Age (years) } & \multicolumn{2}{|c|}{ Mortality } \\
\hline & & & \multicolumn{2}{|c|}{ Female } & \multicolumn{2}{|c|}{ Male } & \multirow{2}{*}{$\begin{array}{c}\text { mean } \\
(\min -\max )\end{array}$} & \multirow{2}{*}{ s. d. } & \multirow{2}{*}{$\mathrm{n}$} & \multirow{2}{*}{$\%$} \\
\hline & $\mathrm{N}$ & $\%$ & $\mathrm{n}$ & $\%$ & $\mathrm{n}$ & $\%$ & & & & \\
\hline Acute & 43 & 35.2 & 14 & 32.5 & 29 & 67.5 & $\begin{array}{c}12.6 \\
(1-17)\end{array}$ & 3.7 & 10 & 23.3 \\
\hline Chronic & 79 & 64.8 & 26 & 33 & 53 & 67 & $\begin{array}{c}12.6 \\
(4-17)\end{array}$ & 3.6 & 3 & 3.8 \\
\hline Total & 122 & 100 & 40 & 32.8 & 82 & 67.2 & & & 13 & 10.7 \\
\hline
\end{tabular}

$\min =$ minimum; $\max =$ maximum; s. $d .=$ standard deviation.

Table 3. Mortality rate by type of surgical procedures performed in the 43 non-adult patients diagnosed with acute osteomyelitis at the Coimbra University Hospital.

\begin{tabular}{lccccc}
\hline Treatment & \multicolumn{2}{c}{ Cases } & \multicolumn{2}{c}{ Mortality } \\
& $\mathrm{N}$ & $\%$ & $\mathrm{n}$ & $\%$ \\
& 23 & 53.5 & 5 & 21.7 \\
\hline Trepanation & 16 & 37.2 & 5 & 31.3 \\
Resection & & & & \\
Incision-sequestrectomy- & 4 & 9.3 & 0 & 0 \\
osteoclasia & & & & & \\
\hline
\end{tabular}




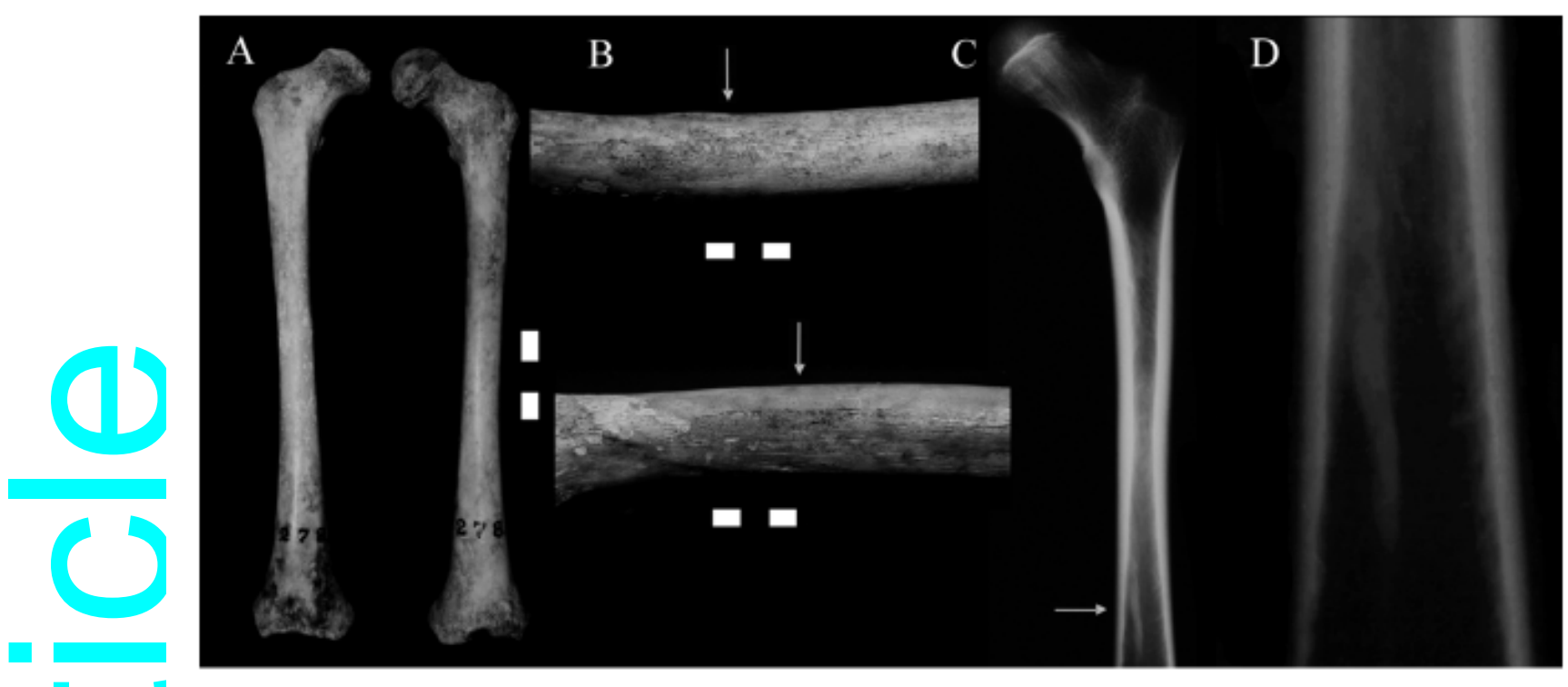

Figure 1. A. Femora from individual 278. B. Close up of the diaphysis showing the small area of bone formation in the left femur. C. Radiographic image of the femur with the arrow pointing to an area of radiodensity in the narrow cavity. D. Close up of the radiodense area. Scale is $3 \mathrm{~cm}$ long.

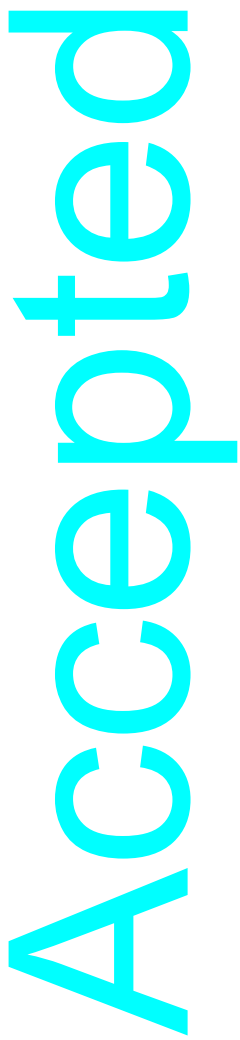




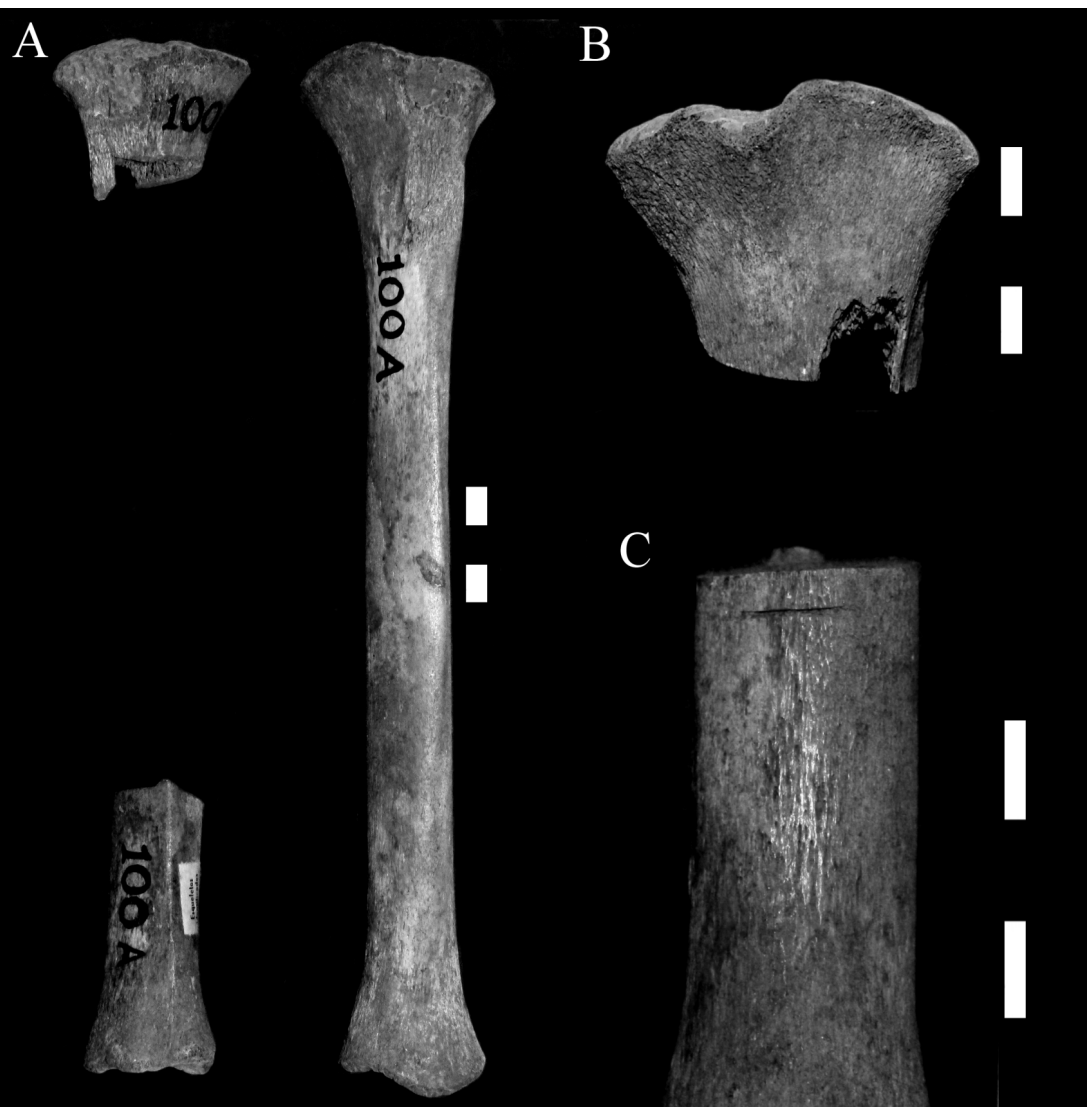

Figure 2. Tibiae of an 11-year-old boy. A. The diaphysis of the right bone was resected. B. Close up of the upper metaphysis. C. A small surgical cut is visible in the lower portion of the diaphysis. Scale is $3 \mathrm{~cm}$ long.

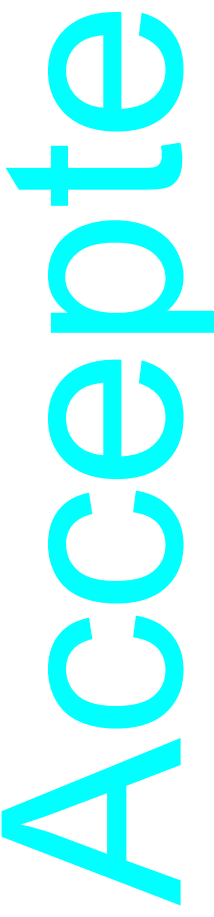



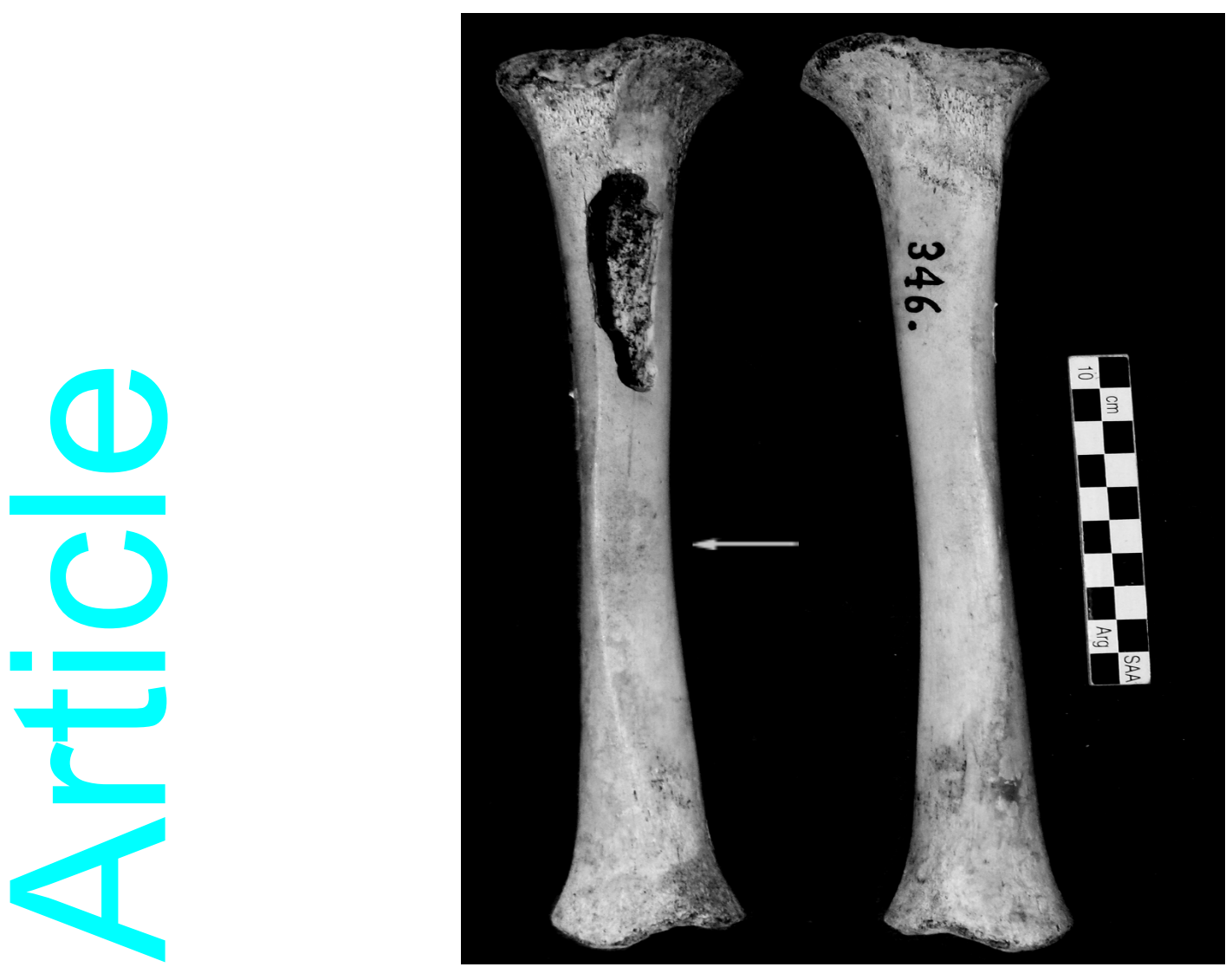

Figure 3. A. Tibiae from individual 346. The upper diaphysis of the right bone shows the opening produced by trepanation. The arrow points to a slight area of new bone formation. 


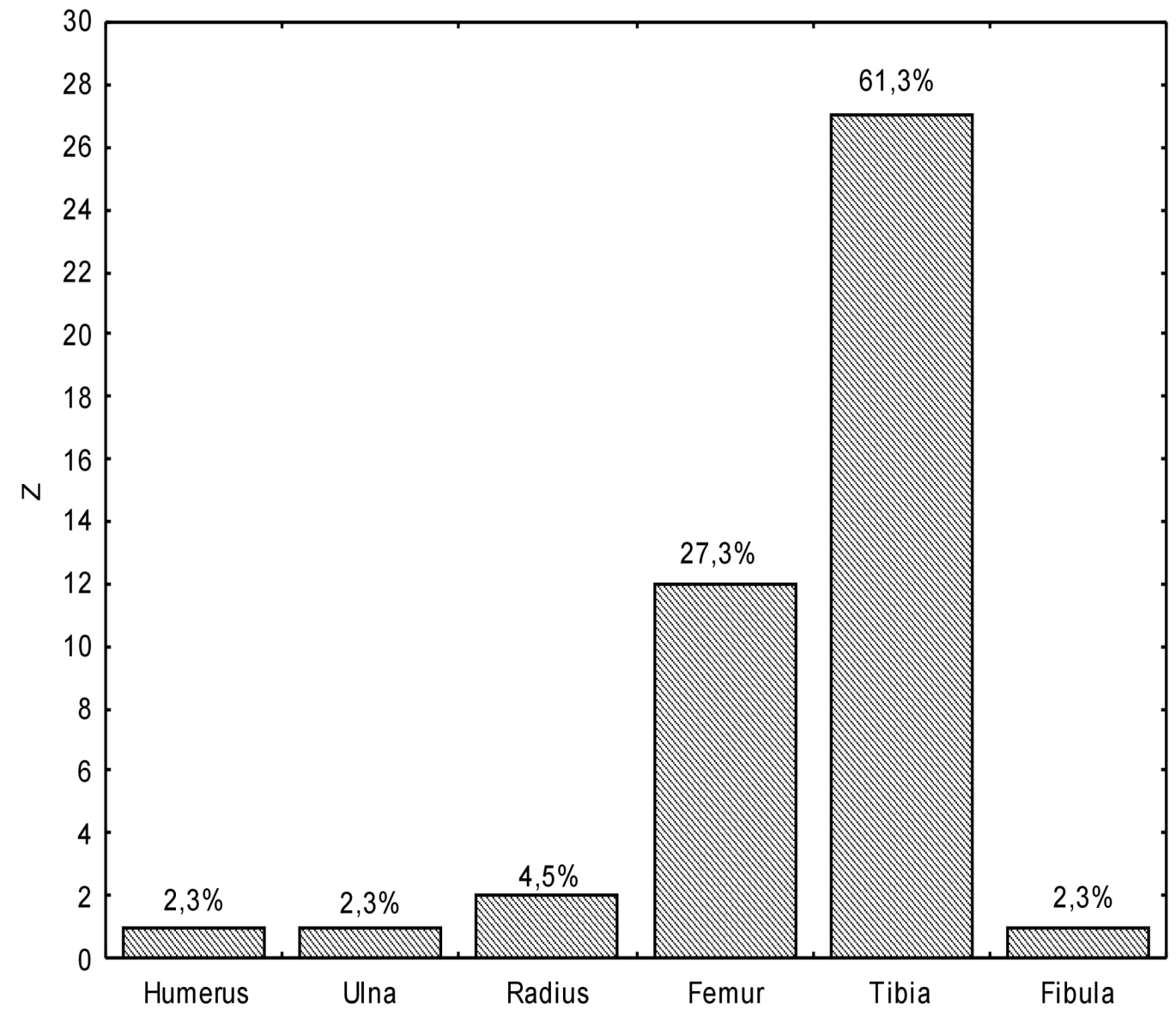

Figure 4. Number and percentage of bones affected by acute osteomyelitis in non-adult individuals admitted to surgery at the Coimbra University Hospital between 1923 and 1929 . 